\title{
Is Lumbar Puncture Needed? - Noninvasive Assessment of ICP Facilitates Decision Making in Patients with Suspected Idiopathic Intracranial Hypertension
}

\section{Lumbalpunktion notwendig? - Die nichtinvasive Erfassung des intrakraniellen Drucks ermöglicht die Entscheidungsfindung bei Patienten mit Verdacht auf idiopathische intrakranielle} Hypertension

\section{(ㄷ) (i) 우) $\odot$}

Authors

Bernhard Schmidt ${ }^{1}$, Marek Czosnyka², Danilo Cardim³ ${ }^{3}$ Zofia Czosnyka², Bernhard Rosengarten ${ }^{1}$

Affiliations

1 Neurology, Klinikum Chemnitz gGmbH, Chemnitz, Germany

2 Brain Physics Laboratory, Clinical Neurosciences, University

of Cambridge, United Kingdom of Great Britain and Northern Ireland

3 Neurology, The University of Texas Southwestern Medical Center, Dallas, United States

Key words

idiopathic intracranial hypertension, lumbar puncture, transcranial Doppler ultrasonography, noninvasive ICP, pseudotumor cerebri

received 05.02.2021

accepted 25.06.2021

published online 08.09.2021

\section{Bibliography}

Ultraschall in Med 2023; 44: e91-e98

DOI 10.1055/a-1586-6487

ISSN 0172-4614

(C) 2021. The Author(s).

This is an open access article published by Thieme under the terms of the Creative Commons Attribution-NonDerivative-NonCommercial License, permitting copying and reproduction so long as the original work is given appropriate credit. Contents may not be used for commecial purposes, or adapted, remixed, transformed or built upon. (https://creativecommons.org/licenses/by-nc-nd/4.0/)

Georg Thieme Verlag KG, Rüdigerstraße 14,

70469 Stuttgart, Germany

\section{Correspondence}

Dr. Bernhard Schmidt

Neurology, Klinikum Chemnitz gGmbH, Dresdner Str. 178, 09116 Chemnitz, Germany

Tel.: Tel.:+4937133312358

b.schmidt@skc.de

\section{ABSTRACT}

Purpose Idiopathic intracranial hypertension (IIH) usually occurs in obese women of childbearing age. Typical symptoms are headache and sight impairment. Lumbar puncture (LP) is routinely used for both diagnosis and therapy (via cerebrospinal fluid drainage) of IIH. In this study, noninvasively assessed intracranial pressure (nICP) was compared to LP pressure (LPP) in order to clarify its feasibility for the diagnosis of IIH. Materials and Methods nICP was calculated using continuous signals of arterial blood pressure and cerebral blood flow velocity in the middle cerebral artery, a method which has been introduced recently. In 26 patients $(f=24, m=2$; age: $33 \pm 11$ years), nICP was assessed one hour prior to LPP. If LPP was $>20 \mathrm{cmH}_{2} \mathrm{O}$, lumbar drainage was performed, LPP was measured again, and also nICP was reassessed.

Results In total, LPP and nICP correlated with $\mathrm{R}=0.85$ $(p<0.001 ; N=38)$. The mean difference of nICP-LPP was $0.45 \pm 4.93 \mathrm{cmH}_{2} \mathrm{O}$. The capability of nICP to diagnose increased LPP ( LPP > $20 \mathrm{cmH}_{2} \mathrm{O}$ ) was assessed by ROC analysis. The optimal cutoff for nICP was close to $20 \mathrm{cmH}_{2} \mathrm{O}$ with both a sensitivity and specificity of 0.92 . Presuming $20 \mathrm{cmH}_{2} \mathrm{O}$ as a critical threshold for the indication of lumbar drainage, the clinical implications would coincide in both methods in 35 of 38 cases.

Conclusion The TCD-based nICP assessment seems to be suitable for a pre-diagnosis of increased LPP and might eliminated the need for painful lumbar puncture if low nICP is detected.

\section{ZUSAMMENFASSUNG}

Ziel Die idiopathische intrakranielle Hypertension (IIH) tritt bevorzugt bei adipösen Frauen im gebärfähigen Alter auf. Typische Symptome sind dabei Kopfschmerz und Sehstörungen. Bei Verdacht auf IIH wird die Lumbalpunktion (LP) routinemäßig sowohl zur Diagnosefindung als auch zur Therapie mittels Liquordrainage verwendet. Durch Vergleich mit dem 
Liquordruck (LPP) soll in dieser Studie die Eignung des nichtinvasiv erfassten intrakraniellen Drucks (nICP) zur IIH-Diagnose untersucht werden.

Material und Methode Der nICP wird dafür aus kontinuierlichen Kurven des arteriellen Blutdrucks und der Blutströmungsgeschwindigkeit berechnet. Bei 26 Patienten $(f=24$, $\mathrm{m}=2$; Alter: $33 \pm 11$ Jahre) wurde der nICP eine Stunde vor der Lumbalpunktion erfasst. Bei einem LPP über $20 \mathrm{cmH}_{2} \mathrm{O}$ wurde eine Liquordrainage durchgeführt, danach wurden sowohl LPP als auch nICP nochmals ermittelt.

Ergebnisse Insgesamt korrelierten LPP und nICP mit $r=0,85$ $(p<0,001 ; n=38)$. Als mittlere Differenz von LPP-nICP ergab sich $0,45 \pm 4,93 \mathrm{cmH}_{2} \mathrm{O}$. Die Eignung des nICP zur Diagnose eines über $20 \mathrm{cmH}_{2} \mathrm{O}$ erhöhten LPP wurde mittels ROC-Analyse geklärt. Der optimale Schwellenwert des nICP lag bei $19,99 \mathrm{cmH}_{2} \mathrm{O}$ bei einer Sensitivität und Spezifität von jeweils 0,92 . Bei angenommenen $20 \mathrm{cmH}_{2} \mathrm{O}$ als kritischer Wert für die Indikation der Liquordrainage stimmten in 35 der 38 Fälle die klinischen Implikationen von LPP und nICP überein.

Schlussfolgerungen Die nICP-Erfassung erscheint für die Prädiagnose eines erhöhten Lumbaldrucks geeignet und könnte bei niedrigen nICP-Werten den Patienten eine Lumbalpunktion ersparen.

\section{Introduction}

Idiopathic intracranial hypertension (IIH), also called pseudotumor cerebri (PTC), usually occurs in obese women of childbearing age [1], although pediatric cases are not uncommon [2]. The typical symptoms are headache, sight impairment, and vertigo. In the case of persistently increased intracranial pressure (ICP), the risk of permanent visual loss is high. Lumbar puncture is a common procedure in $\mathrm{IIH}$. It is used for both diagnosis and treatment of increased ICP. For diagnostic purposes, the lumbar puncture pressure (LPP) is assessed by the height of the column of cerebrospinal fluid (CSF) in a manometer tube. In the case of pathologically increased LPP, IIH short-term treatment consists of draining some volume, e. g., $30 \mathrm{ml}$, of CSF. For long-term treatment, medication that decreases CSF production is usually considered. Due to its invasive and sometimes painful nature, lumbar puncture is not always tolerated by patients. Moreover, pain and stress may cause an unstable LPP. For these reasons, different techniques have been introduced to estimate ICP noninvasively (nICP). Ophthalmoscopy is used for measuring protrusion of the papillary disc as an indirect sign of increased ICP. Similarly, duplex sonography assesses papillary prominence as well as the diameter of the optic nerve sheath to evaluate ICP [3, 4]. In cerebral MRI scans, IIH is indicated by the appearance of an empty sella [5]. Although these and other MRI-based techniques [6-8] are used in clinical practice, they do have some limitations regarding their accuracy [9].

In our study we adopted an established technique from neurocritical care for the assessment of nICP [10-14]. nICP was calculated from simultaneous Doppler recording of intracranial cerebral blood flow velocity (CBFV) and noninvasive arterial blood pressure recording at brain level according to the algorithm summarized in - Fig. 1 and was compared to LPP readings. Noninvasive and invasive data were correlated and a cutoff level for distinguishing normal from increased LPP was determined by ROC analysis.

\section{Materials and Methods}

26 patients with suspected $\mathrm{IH}(\mathrm{f}=24, \mathrm{~m}=2$; age $=33 \pm 11$ years $)$ treated at our hospital were included in this prospective study. All of them presented with clinical symptoms of idiopathic intra- cranial hypertension: chronic headaches, ophthalmologic changes, and/or vertigo plus attention impairment and chronic fatigue. Patients underwent cerebral MRI with angiography, ophthalmoscopic investigations, and LP. nICP was assessed one hour prior to LP. If LPP was above $20 \mathrm{cmH}_{2} \mathrm{O}(\sim 15 \mathrm{mmHg})$, lumbar drainage of $10-30 \mathrm{ml}$ of CSF was performed. This was part of our institutional protocol for the management of IIH [15]. In such cases, LPP was measured again immediately after drainage, and, if possible, nICP was reassessed.

\section{Monitoring}

nICP was assessed in patients resting in a supine position on a comfortable diagnostic chair. CBFV was assessed by transcranial Doppler (TCD) ultrasound technique. A 2-MHz pulsed Doppler monitoring device (Multidop-P, DWL, Sipplingen, Germany) was used for bilateral assessment of the TCD signal in the middle cerebral artery (MCA) at a depth of about 55-65 mm. TCD probes were secured in place using a headset provided by the device manufacturer. ABP was continuously noninvasively measured with a tonometric sensor device (Colin CBM 7000, ScanMed Medical Instruments, Moreton-in-Marsh, UK), placed on the radial artery, which regularly calibrates by a standard arm cuff using oscillometric techniques [16]. The measuring level was adjusted to the level of the MCA. A personal computer fitted with data acquisition systems (Daq 112B, lotech, Inc., Cleveland, OH, USA) and software developed in-house [10] was used for 30 minutes of recording and analyzing CBFV and ABP signals and for bilateral calculation of nICP signals during this time period ( $\mathbf{F i g . 2}$ ). The sampling frequency was $25 \mathrm{~Hz}$. The averaging of the calculated nICP signals on both sides resulted in a single nICP value which was compared to the LPP.

\section{Lumbar puncture}

The lumbar pressure measurement procedure followed standardized recommendations [17]. Puncture was performed with atraumatic 22-gauge lumbar puncture needles. Patients were positioned in a comfortable lateral decubitus position, with the vertebrae in line in the horizontal plane and the head in a neutral position on a pillow with the knees flexed. The needle was inserted in the midline of the spine, at the same level as the patient's head. An aseptic technique was required as described in the arti- 


\section{PATIENT SIGNALS}

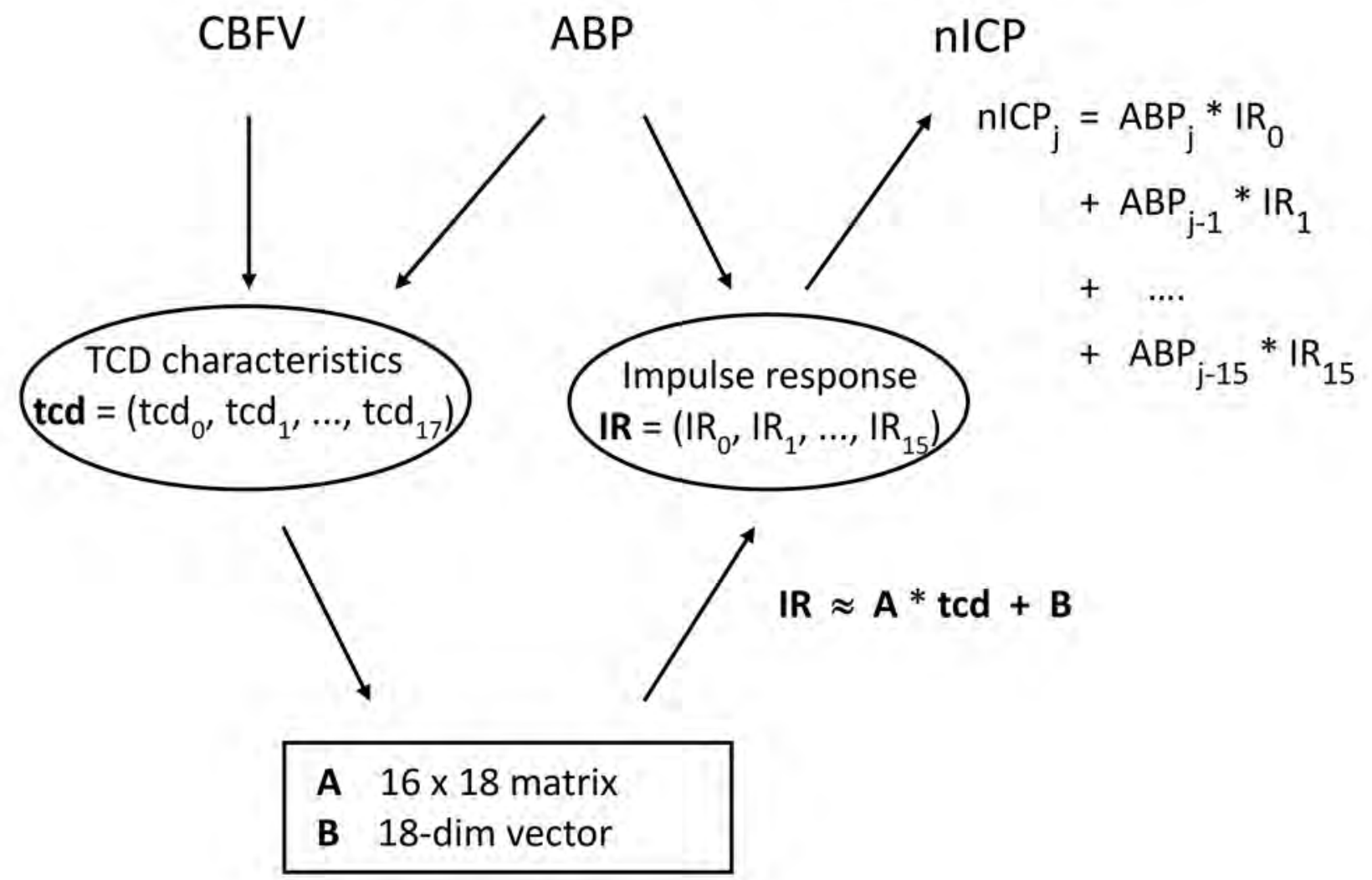

ESTIMATED ICP

$\mathrm{nICP}$

- Fig. 1 Calculation of nICP. From measured CBFV and ABP, 18 selected TCD characteristics are derived and multiplied with the nICP procedure matrix $A$. After adding the vector $B$, this yields the $A B P->I C P$ impulse response, a discrete function of 16 coefficients which transforms the $A B P$ signal into the nICP signal. In detail, the current $\mathrm{nICP}$ is calculated as the weighted sum of the current ABP and 15 preceding ABP samples. The 16 impulse response coefficients are used as ABP weights. The TCD characteristics essentially consist of the ABP->CBFV impulse response together with additional ICP-related parameters. According to the side of MCA insonation, right and left nICP signals were calculated separately and later put together and averaged over a 30-minute period. nICP procedure matrix A and vector B were previously calculated using a signal database of approximately 200 reference patients (traumatic brain injuries: 75\%, stroke and other non-traumatic brain diseases: $25 \%$ ). The stored signals consisted of CBFV, ABP, and ICP (invasively assessed by intraparenchymal or intraventricular pressure probes). Multiple regressions were used to express the relationship between TCD characteristic and ABP->ICP impulse response in terms of $A$ and $B$.

cles. Lumbar puncture was performed between the $4^{\text {th }}$ and $5^{\text {th }}$ spinous process. Once the needle was in the intradural space, the stylet was withdrawn slowly while waiting a few seconds to see if CSF emerges. Once CSF was seen, the manometer (a three-way tap attached to the end of a commercial manometer) (Pajunk, spinal manometer, Geisingen, Germany) was connected. After one minute, the pressure was obtained, when the meniscus of CSF on top of the manometer oscillated with respiration. If CSF drainage was intended, CSF was withdrawn by rotating the threeway tap and collecting CSF in specimen bottles.

\section{Noninvasive assessment of ICP}

\section{General description}

A basic consideration might motivate the usage of CBFV and $A B P$ for ICP assessment. In a most simplistic cerebral circulation mod- el, with one vessel of constant diameter (Dc) and constant cerebral blood flow resistance (Rc), cerebral perfusion pressure (CPP) equals the product of cerebral blood flow (CBF) and Rc. However, $C B F$ is the product of CBFV and Dc, while CPP equals the difference $A B P-I C P$. This results in the equation $A B P-I C P=C B F V * D c^{*} R c$ from which ICP can easily be calculated from CBFV and ABP signals. Using more realistic physiologic models, applications of TCD for nICP monitoring are conceivable if one considers the insonated compliant artery, such as the MCA, as a biological pressure transducer whose walls can be deflected by transmural pressure (equivalent to CPP in the intracranial compartment), modulating the CBFV pulsatile waveform.

\section{Our model}

In the model utilized in this study, the intracranial compartment is considered a black-box system, with ICP being a system response 


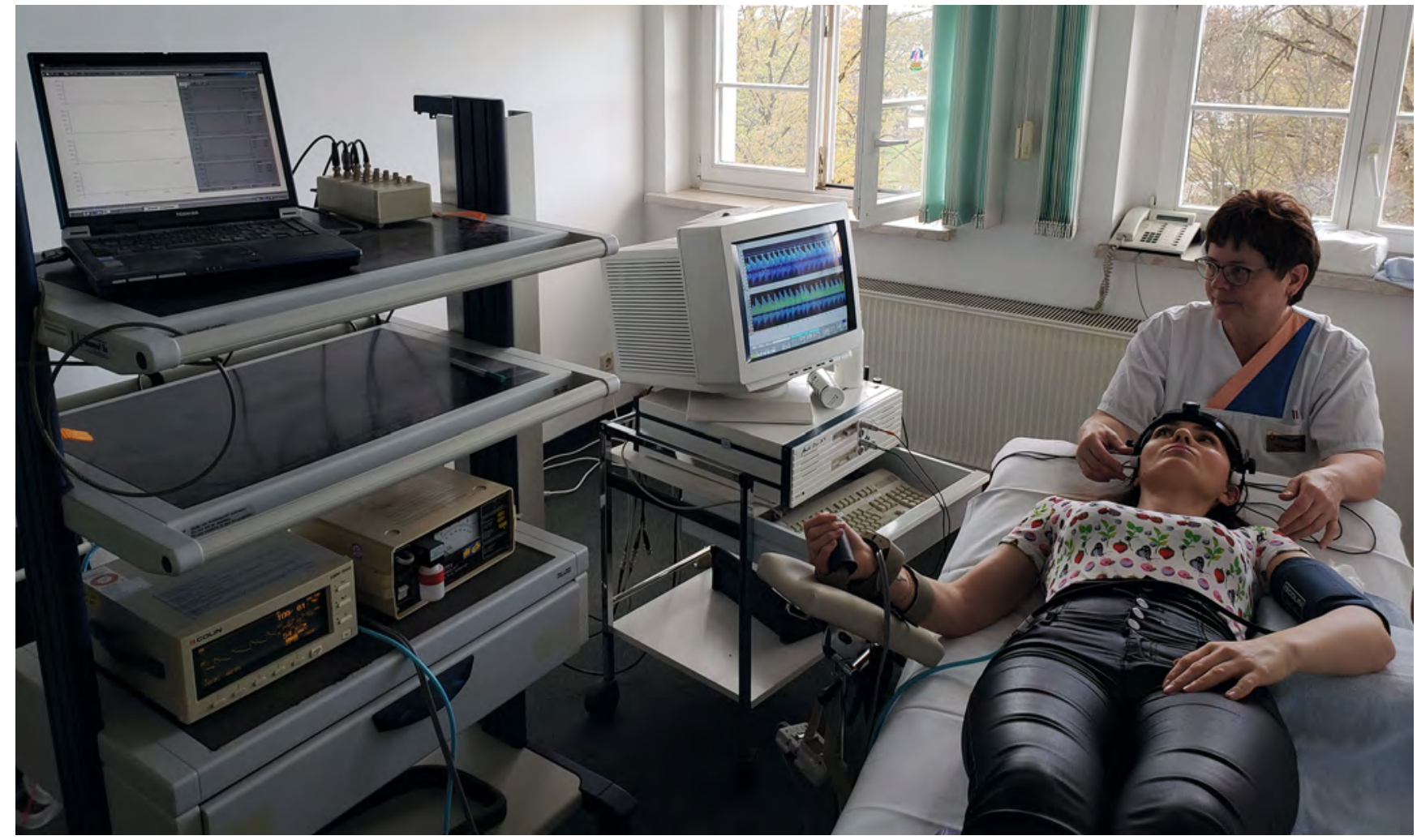

- Fig. 2 Study workup. The study workup is presented by two employees of our hospital. The ABP pressure sensor is mounted at the right radial artery of the patient, and the pressure cuff for ABP mean value calibration is located on left upper arm. Both of them are connected to the Colin ABP device (bottom left). The left upper arm is elevated to keep the cuff at head level. Two TCD monitoring probes fixed by a headset are located for bilateral insonation of the MCA. The analog output signals of both the ABP and the Doppler device (in the middle) are connected to a laptop (top left) and converted into digital signals, which were stored and displayed on the monitor using our in-house software. At the time the picture was taken, mask wearing was not required in our hospital.

to the incoming signal ABP. This mathematical model provides a method to describe the transmission characteristics, with input and output signals. The intracranial compartment is modelized by a so-called impulse response function which connects the assumed input signal, ABP, with the output signal, ICP. Then, two linear models are established to depict the relationship between $A B P$ and ICP (ABP $\rightarrow I C P$ model) and the relationship between ABP and FV with the application of certain TCD characteristics [10] ( $\triangleright$ Fig. 1). The TCD characteristics may be derived from ABP and CBFV signals and, therefore, can be assessed noninvasively from the patient. The essential part of our nICP procedure is a description of the relationship between the TCD characteristics and the $\mathrm{ABP} \rightarrow$ ICP model. A signal database including invasively assessed ICP of reference patients was used for this purpose. Therefore, the ABP $\rightarrow$ ICP model can be calculated from TCD characteristics, and its output data provides a continuous nICP waveform.

\section{Statistics}

For evaluations we used the statistical software BIAS V11.01, developed at Goethe-University, Frankfurt (epsilon-Verlag GbR, Germany). Test results with probability $\mathrm{P}<0.05$ were considered significant.

\section{Comparison between LPP and nICP}

Pearson correlation was applied to pairs of corresponding nICP and LPP values. Normal distribution was tested by Shapiro-Wilk test. Deviations between nICP and LPP were assessed in terms of mean difference (MD) and its standard deviation (SD). The limits of agreement ( $L A)$ of probability $P=0.95$ may be estimated by the interval (MD-2*SD, MD $+2 * S D)$ in the case of normal distribution. The significance of sample differences were ascertained by paired student's t-tests.

\section{Suitability for LP decision finding}

Receiver operating curve (ROC) analysis was used to assess the accuracy of nICP for predicting an LPP above $20 \mathrm{cmH}_{2} \mathrm{O}$. A parametric curve of sensitivity versus (1-specificity) is plotted. The area under the curve (AUC) indicates the suitability of the investigated method. It may range from 0.5 (poor predictive value, either sensitivity or specificity being below 0.5 ) to 1.0 (high predictive value). The significance of the result was determined by exclusion of the Ho hypothesis (i. e., $A \cup C=0.5$ ). For this, asymptotic Wilcoxon-Mann-Whitney test as well as the DeLong test [18] were performed. 


\section{Ethics}

The study was approved by the local ethics committee (EK-BR-8/ 17-1). All patients agreed to participate in the study by informed consent. Lumbar puncture was part of the clinical routine in the case of suspected IIH as well as follow-up treatment.

\section{Results}

\section{Patients}

All patients were investigated with simultaneous LLP and nICP measurements. In 10 of the 26 patients, IIH was diagnosed. In 5 patients, one additional assessment of nICP versus LPP was performed with time lags of 3 weeks, 3 months ( 3 patients), and 11 months between initial and control assessments. Due to measured increased LPP (the threshold accepted in our center is $>=20 \mathrm{cmH}_{2} \mathrm{O}$ ), lumbar drainage was performed in 15 cases. In 7 of these patients, LPP was measured again directly after drainage and compared to nICP which was reassessed 2 hours later.

\section{Comparison between LPP and nICP}

In total, 38 data pairs of LPP and nICP were compared (26 patients +5 control assessments +7 reassessments after drainage). They correlated strongly with each other, showing $R=0.85(p<0.001$; $\mathrm{N}=38$ ) ( $\vee$ Fig. 3) The normal distribution of differences was verified by Shapiro-Wilk test $(p=0.6 ; N=38)$. The mean difference \pm standard deviation (MD $\pm \mathrm{SD}$ ) of nICP-LPP was $0.45 \pm 4.93 \mathrm{~cm} \mathrm{H}_{2} \mathrm{O}$, and the mean absolute difference was $4.02 \mathrm{cmH}_{2} \mathrm{O}$ ( $\triangleright$ Fig. 4). After lumbar drainage, nICP dropped significantly from $22.4 \pm 2.3$ to $16.2 \pm 1.9 \mathrm{H}_{2} \mathrm{O}(\mathrm{P}<0.001$, paired student's t-test; $\mathrm{N}=7)$. On the subject level (i. e., excluding control cases and reassessment after drainage), nICP and LPP correlated with $R=0.86$ ( $p<0.001$; $\mathrm{N}=26$ ). $\mathrm{MD}$ was $0.20 \pm 4.47 \mathrm{cmH}_{2} \mathrm{O}$. If only those cases with nICP reassessed after drainage were excluded from evaluation, nICP and LPP correlated with $R=0.85$ ( $p<0.001 ; N=31)$. MD was $-0.57 \pm 4.76 \mathrm{~cm} \mathrm{H}_{2} \mathrm{O}$. A student's t-test on all 38 data pairs showed no significant differences between both methods $(p=0.59)$. Considering a difference $>=3 \mathrm{cmH}_{2} \mathrm{O}$ between two pressure samples as relevant, a number of 38 data pairs with SD (of $\mathrm{MD}$ ) $=4.93 \mathrm{cmH}_{2} \mathrm{O}$, the power of this test was 0.96 .

\section{Suitability for LP decision finding}

The capability of nICP to diagnose increased LPP above $20 \mathrm{cmH}_{2} \mathrm{O}$ was assessed using ROC analysis of all data. The optimal cutoff value for nICP was $19.99 \mathrm{cmH}_{2} \mathrm{O}$ with both a sensitivity and specificity of 0.92 . The AUC was $0.95(P<0.001$, both Wilcoxon Mann Whitney and DeLong test, $\mathrm{N}=38$ ) ( Fig. 5). Using $20 \mathrm{cmH}_{2} \mathrm{O}$ as the critical threshold for a need for lumbar drainage in 35 of 38 cases, the clinical implications would have been the same in both methods ( $>$ Fig. 3 ).

\section{Discussion}

The nICP showed good agreement with invasive LPP readings in terms of absolute pressure values. Moreover, both methods large-
Scatter Plot: LPP (y-axis) versus nICP (x-axis), $R=0.85$



- Fig. 3 LPP versus nICP in 38 cases of 26 patients. LPP significantly correlates with nICP with $R=0.85(p<0.001)$. The red lines highlight the critical threshold of $20 \mathrm{cmH}_{2} \mathrm{O}$ for clinical indication of lumbar drainage. The dots which are either in the upper right or lower left represent cases with concordant clinical implications in both methods. The results were contradictory in only 3 cases.

ly agreed if used as the diagnostic tool for the indication for CSF drainage. nICP might help to avoid LP, which is often painful and carries a risk of infection.

\section{Data consideration}

In view of its suitability to assess both increased and normal ICP, it was expedient to compare nICP to LPP before and -if applicableafter lumbar drainage. A decrease of ICP together with the reduction of CSF volume should cause a status change in the investigated pressure-volume system. Therefore, both observations were assumed to be independent. Reassessment of nICP in seven patients was performed within two hours after lumbar drainage and showed a pressure decrease. However, the reproduction of CSF during these two hours could have reduced the effect of drainage and may have introduced an additional error. In five patients, LPP and nICP assessment was repeated after readmission. Due to lengthy time lags between their visits, the cases were treated as independent cases. One might assume that there is some individual specificity in the relationship between CBFV, $A B P$, and ICP which remains over time and might introduce a bias to the statistical evaluation. However, our assumption of (almost) independence was supported by a formerly published study [19], where it was found that individual aspects changed rather rapidly over time. Nevertheless, some additional evaluations were performed in order to rule out the influence of bias or random effects caused by reassessments. Thus, basic statistics had been repeated in two subgroups, which did not contain cases of nICP reassess- 
Bland-Altman plot: nICP-LPP ( $y$-axis) versus (nICP+LPP)/2 ( $\mathrm{x}$-axis) nICP - LPP [C $\left.\mathrm{CmH}_{2} \mathrm{O}\right]$



- Fig. 4 Bland-Altman plot comparison between LPP and nICP in 38 data pairs. MD \pm SD of nICP-LPP is $0.45 \pm 4.93 \mathrm{cmH} 2 \mathrm{O}$ with Cl95 being $(-1.2,2.1)$. The difference LPP-nICP slightly increases with increasing pressure $(\mathrm{nICP}+\mathrm{LPP}) / 2$. The plot trend line intersects the line of equal LPP and nICP $(\mathrm{nICP}-\mathrm{LPP}=0)$ at a pressure close to 20 $\mathrm{CmH}_{2} \mathrm{O}$. The limits of agreement are $(-8.1050,9.0019)$ for $\mathrm{P}=0.90$ and $(-9.8242,10.7211)$ for $P=0.95$. The blue line indicates the mean difference of nICP-LPP, and the dotted blue and green lines show the $L A$ for $P=0.90$ and 0.95 . MD, SD: mean difference, standard deviation. $\mathrm{Cl95}: \mathrm{P}=0.95$ confidence interval of MD. LA: limits of agreement

\section{ROC analysis of nICP diagnostic test: Sensitivity (y-axis)} versus 1 -Specificity ( $x$-axis)

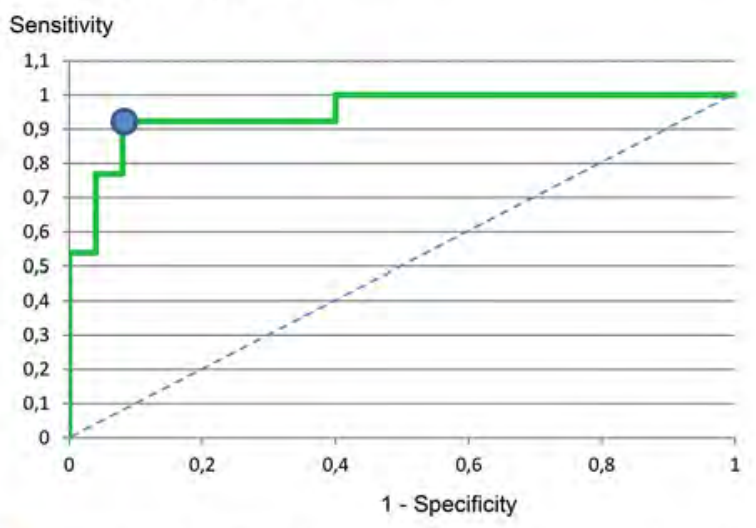

Optimal nICP Cutoff: $19.99 \mathrm{cmH}_{2} \mathrm{O}$, Sensitivity: 0.92 , Specificity: 0.92

- Fig. 5 ROC analysis of nICP diagnostic test. The blue dot indicates the optimal cutoff for the prediction of increased LPP $>20 \mathrm{cmH}_{2} \mathrm{O}$. The cutoff is $\mathrm{nICP}=19.99 \mathrm{cmH}_{2} \mathrm{O}$ with both the sensitivity and specificity $=0.92$. The area under the ROC curve is 0.95 . The area under the dotted line is 0.5 . It represents a completely unsuitable test with either sensitivity or specificity $<=0.5$. ROC: receiver operating characteristic. ment. However, the results were similar to the results of the complete cohort.

\section{TCD characteristics}

The nICP procedure uses TCD characteristics for a control of the $\mathrm{ABP} \rightarrow \mathrm{ICP}$ transmission. Although there are some typical characteristics in the shape of CBFV pulse waveforms ( $\triangleright$ Fig. 6) which may indicate increased ICP, optical impression can be misleading. The reason for this is that the concept of TCD characteristics involves an advanced analysis of the $A B P \rightarrow C B F V$ relationship which provides additional control factors in the nICP procedure.

\section{Application of nICP}

In our study, we followed a special study protocol by using specialized software to calculate nICP and a specialized setting of devices. However, common use of this method is possible with modified equipment and a simplified examination. Meanwhile, a new device (Delica EMF-9 d pro, Shenzen Delica Medical Equipment Co., China) has become commercially available which combines bilateral TCD and Finapres ABP (Finapres NOVA, Finapres Medical Systems BV, Enschede, The Netherlands) assessment. Moreover, monitoring software (ICM+, Cambridge Enterprise, University of Cambridge, UK) is integrated together with an nICP software plugin which performs our method algorithms. Moreover, ICM+ is also available as pure software, which can be used in individual device configurations. In a prior study evaluating patients with hydrocephalus [20], the Finapres noninvasive ABP method was shown to be suitable for nICP assessment as well. Both Colin and Finapres systems can be calibrated by arm cuff measurement of ABP.

In our study, the acquisition time was 30 minutes. However, for clinical use, 10 minutes of signal assessment and unilateral TCD is completely sufficient for reliable results. Generally, the insonation side does not matter. However, in the case of vessel stenosis occurring on one side, the other side should be chosen.

\section{nICP and other noninvasive methods}

Different methods of nICP assessment have been reported so far, like MRI-based methodology [6-8, 21], optic nerve sheath diameter (ONSD) [4, 9, 22-24], and tympanic membrane displacement [25-28]. Although some of them show a high correlation with ICP, none of them have yet reached wider application in clinical practice, nor have they been able to act as a substitute for LPP. nICP may be used to decide whether or not LP should be performed. However, a combination of different noninvasive methods might help to increase reliability and acceptance. Especially, if combined with ONSD, nICP might be helpful for diagnostic decisions and may rule out diagnosis of $\mathrm{IIH}$ or indicate medication change.

\section{Limitations}

A closer examination of IIH with its complex disease pattern was beyond the scope of this study. Moreover, the results cannot be transferred to pediatric patients without specific investigation. Our study only focused on the coincidence of nICP and LPP and its possible clinical application in IIH diagnosis. LPP was used as 


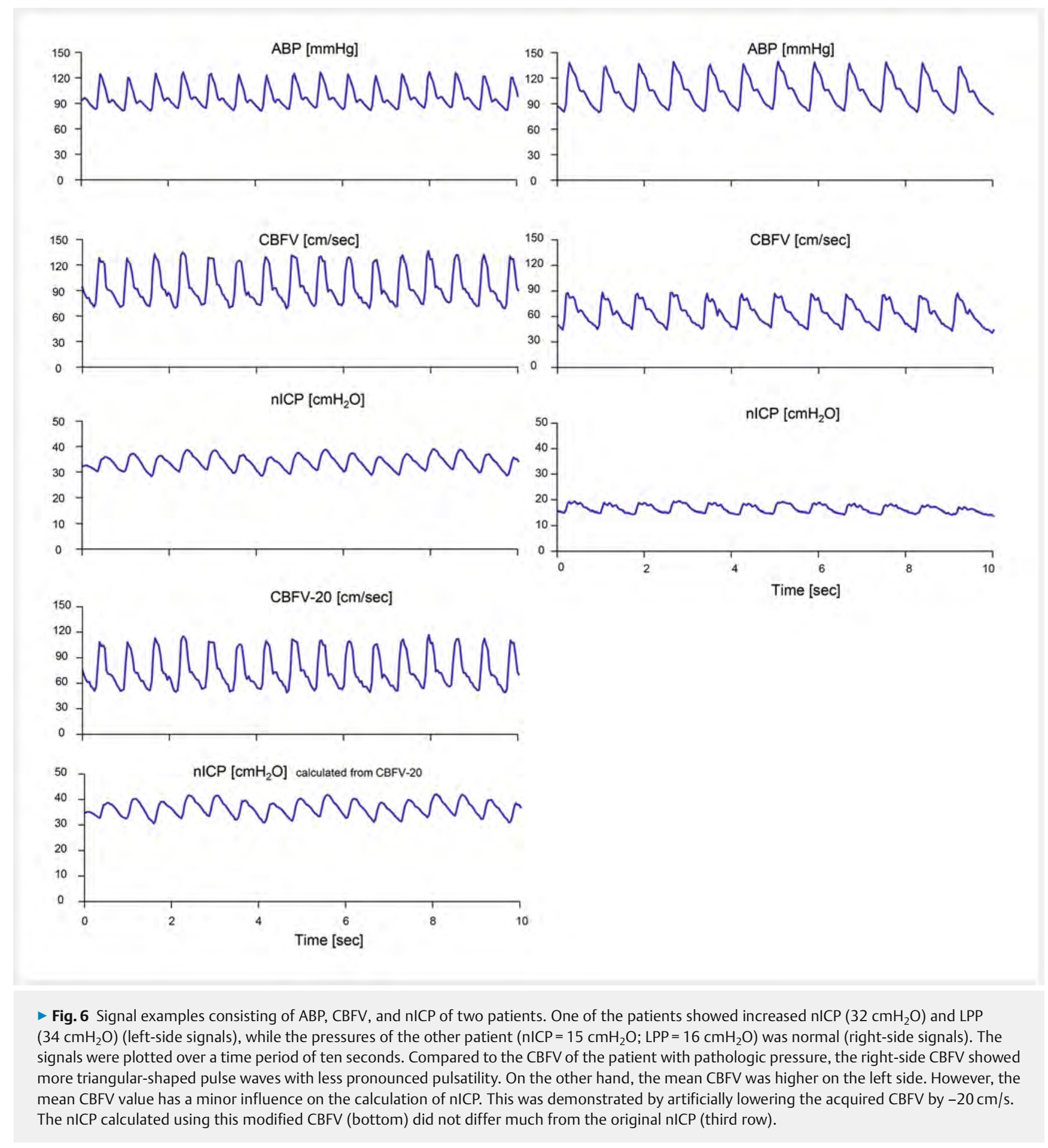

the gold standard. Potential errors of LPP assessment and their impact on the results could not be evaluated in this study.

The number of studied patients was small, and more patients need to be included to confirm the current conclusions. In addition, the study power was calculated. While power assesses the probability of overlooking significance, we presented significant results, even with a small population. In our case, power calculation confirmed the non-significance of the difference between the LPP and nICP methods.
The Bland-Altman plot shows a positive correlation between pressure difference (LPP - nICP) and the average pressure $((\mathrm{LPP}+\mathrm{nICP}) / 2)$ $(\triangleright$ Fig.4). This means that the scope of assessed nICP was reduced compared to LPP. nICP underestimated high LPP and overestimated low LPP. This was also the reason for the rather extended limits of agreement of both pressures. However, in the range around $20 \mathrm{cmH}_{2} \mathrm{O}$ [29] which is the critical range for lumbar drainage decision, nICP and LPP agreed properly. 
In some patients, we additionally insonated the optic nerve sheath and estimated its diameter (ONSD). However, so far, this has not been done systematically and, therefore, we did not mention any results here. Further exploration of this issue will be the subject of ongoing study.

\section{Conclusion}

TCD-based assessment of ICP seems to be a promising method for pre-diagnosis of increased LPP which might eliminate the need for an invasive lumbar puncture in cases of low nICP (below $20 \mathrm{cmH}_{2} \mathrm{O}$ ). Moreover, the method might allow patient-friendly long-term monitoring.

\section{Conflict of interest}

B.S. and M.C. have financial interest in a part of licensing fee for noninvasive ICP plugin of ICM+ software.

M.C. and Z.C. were supported by Revert Project, Interreg France (Channel Manche) England, funded by ERDF.

\section{References}

[1] Wakerley BR, Tan MH, Ting EY. Idiopathic intracranial hypertension. Cephalalgia 2015; 35: 248-261. doi:10.1177/0333102414534329

[2] Lalou AD, McTaggart JS, Czosnyka ZH et al. Cerebrospinal fluid dynamics in pediatric pseudotumor cerebri syndrome. Childs Nerv Syst 2020; 36 : 73-86. doi:10.1007/s00381-019-04263-4

[3] De Bernardo M, Vitiello L, Rosa N. Sonographic evaluation of optic nerve sheath diameter in idiopathic intracranial hypertension. J Clin Neurosci 2020; 73: 331-332

[4] Lochner P, Fassbender K, Knodel S et al. B-Mode Transorbital Ultrasonography for the Diagnosis of Idiopathic Intracranial Hypertension: A Systematic Review and Meta-Analysis. Ultraschall in Med 2019; 40: 247252. doi:10.1055/a-0719-4903

[5] Brodsky MC, Vaphiades M. Magnetic resonance imaging in pseudotumor cerebri. Opthalmology 1998; 105: 1686-1693

[6] Alperin N, Lee SH, Loth F et al. MR-Intracranial pressure (ICP): a method to measure intracranial elastance and pressure noninvasively by means of MR imaging: baboon and human study. Radiology 2000; 217: 877885

[7] Alperin N, Kadkhodayan Y, Loth F et al. MRI measurements of intracranial volume change: a phantom study. Proc Intl Soc Mag Reson 2001; 9: 1981

[8] Glick RP, Niebruegge J, Lee SH et al. Early experience from the application of a noninvasive magnetic resonance imaging-based measurement of intracranial pressure in hydrocephalus. Neurosurgery 2006; 59: 10521060

[9] Robba C, Santori G, Czosnyka M et al. Optic nerve sheath diameter measured sonographically as non-invasive estimator of intracranial pressure: a systematic review and meta-analysis. Intensive Care Med 2018; 44: 1284-1294. doi:10.1007/s00134-018-5305-7

[10] Schmidt B, Klingelhöfer ], Schwarze |] et al. Noninvasive prediction of intracranial pressure curves using transcranial Doppler ultrasonography and blood pressure curves. Stroke 1997; 28: 2465-2472

[11] Schmidt B, Czosnyka M, Klingelhöfer J. Clinical applications of a non-invasive ICP monitoring method. Eur J Ultrasound 2002; 16: 37-45

[12] Schmidt B, Czosnyka M, Smielewski P et al. Noninvasive Assessment of ICP: Evaluation of New TBI Data. In: Ang BT, ed.; Intracranial Pressure and Brain Monitoring XV. 122 Acta Neurochir Suppl; 2016: 69-73. doi:10.1007/978-3-319-22533-3_14. Springer International Publishing Switzerland

[13] Cardim D, Robba C, Donnelly J et al. Prospective Study on Noninvasive Assessment of Intracranial Pressure in Traumatic Brain-Injured Patients: Comparison of Four Methods. J Neurotrauma 2016; 33: 792-802. doi:10.1089/neu.2015.4134

[14] Cardim D, Robba C, Schmidt E et al. Transcranial Doppler Non-invasive Assessment of Intracranial Pressure, Autoregulation of Cerebral Blood Flow and Critical Closing Pressure during Orthotopic Liver Transplant. Ultrasound Med Biol 2019; 45: 1435-1445. doi:10.1016/j.ultrasmedbio.2019.02.003

[15] Wüllner U. Idiopathische intrakranielle Hypertension (IIH), S1-Leitlinie 2019, In: Deutsche Gesellschaft für Neurologie, ed. Leitlinien für Diagnostik und Therapie in der Neurologie. Stuttgart. New York: Georg Thieme Verlag; 2019. Online: www.dgn.org/leitlinien

[16] Zorn EA, Wilson BM, Angel |] et al. Validation of an automated arterial tonomtry monitor using Association for the Advancement of Medical Instrumentation standards. Blood Pressure Monitoring 1997; 2: 185188

[17] Doherty CM, Forbes RB. Diagnostic Lumbar Puncture. Ulster Med ] 2014; 83: $93-102$

[18] DeLong ER, DeLong DM, Clarke-Pearson DL. Comparing the areas under two or more correlated receiver operating characteristic curves: a nonparametric approach. Biometrics 1988; 44: 837-845

[19] Schmidt B, Cardim D, Weinhold M et al. Comparison of Different Calibration Methods in a Non-invasive ICP Assessment Model. In: Heldt T, ed.; Intracranial Pressure \& Neuromonitoring XVI. 126 Acta Neurochir Suppl; 2018: 79-84. doi:10.1007/978-3-319-65798-1_17. Springer International Publishing Switzerland

[20] Schmidt B, Czosnyka M, Schwarze J] et al. Evaluation of a method for noninvasive intracranial pressure assessment during infusion studies in patients with hydrocephalus. J Neurosurg 2000; 92: 793-800

[21] Burman R, Shah AH, Benveniste R et al. Comparing invasive with MRIderived intracranial pressure measurements in healthy elderly and brain trauma cases: A pilot study. J Magn Reson Imaging 2019; 50: 975-981. doi:10.1002/jmri.26695

[22] Geeraerts T, Launey Y, Martin L et al. Ultrasonography of the optic nerve sheath may be useful for detecting raised intracranial pressure after severe brain injury. Intensive Care Med 2007; 33: 1704-1711. doi:10.1007/s00134-007-0797-6

[23] Bäuerle J, Nedelmann M. Sonographic assessment of the optic nerve sheath in idiopathic intracranial hypertension. J Neurol 2011; 258 : 2014-2019

[24] Robba C, Cardim D, Tajsic T et al. Ultrasound non-invasive measurement of intracranial pressure in neurointensive care: A prospective observational study. PLOS Med 2017; 14: e1002356 doi:10.1371/journal. pmed.1002356

[25] Reid A, Marchbanks RJ, Burge DM et al. The relationship between intracranial pressure and tympanic membrane displacement. $\mathrm{Br}$ 」 Audiol 1990; 24: 123-129

[26] Samuel M, Burge DM, Marchbanks RJ. Tympanic membrane displacement testing in regular assessment of intracranial pressure in eight children with shunted hydrocephalus. J Neurosurg 1998; 88: 983-995

[27] Shimbles S, Dodd C, Banister K et al. Clinical comparison of tympanic membrane displacement with invasive intracranial pressure measurements. Physiol Meas 2005; 26: 1085-1092

[28] Shulman A, Goldstein B, Marchbanks R]. The tympanic membrane displacement test and tinnitus: preliminary report on clinical observations, applications, and implications. Int Tinnitus J 2012; 17: 80-93

[29] Cardim D, Robba C, Bohdanowicz M et al. Non-invasive Monitoring of Intracranial Pressure Using Transcranial Doppler Ultrasonography: Is It Possible? Neurocrit Care 2016; 25: 473-491. doi:10.1007/s12028-0160258-6 